\title{
Drug developers explore vitamin $D$ benefits without the vitamin
}

Late last year, the US Institute of Medicine released a report stating that research claiming any benefits from vitamin $\mathrm{D}$ beyond building strong bones is "inconsistent and inconclusive." Although inert vitamin D supplements have yet to prove their worth, new research is increasingly showing that active analogs of the molecule can help fight a number of diseases, including cancer and chronic kidney failure.

Physicians already prescribe one such drug-calcitriol, an active form of vitamin D first synthesized in the 1970s-to treat rickets, psoriasis and vitamin D deficiencies sometimes seen with kidney disease.

But there is a drawback to calcitriol: high doses can lead to a surfeit of calcium in the blood, a condition known as hypercalcemia. So investigators have been working to develop other vitamin $\mathrm{D}$ analogs that minimize this risk while maximizing the benefits.

Over the past two decades, various labs have synthesized thousands of such analogs with molecular structures that differ slightly from calcitriol. "Analogs have been tweaked at every possible chemical 'intersection"' says Donald Trump, chief executive of the Roswell Park Cancer Institute in Buffalo, New York.

Some of the analogs have been designed to bind the receptor less tightly, although this compromises their efficacy. Another way to make better vitamin $\mathrm{D}$ drugs would be to develop analogs that have a different half-life in the blood or by finding coactivators of the receptor that only function in certain tissues, says Glenville Jones, a biochemist at Queen's University in Kingston, Ontario, and an author on the IOM's vitamin D report.

To date, clinical research on calcitriol and its analogs has focused mainly on treatment of cancer. In 2002, a company called Novacea (now Transcept) developed a formulation of calcitriol called DN-101. The drug seemed to work well in a phase 2 clinical trial of patients with prostate cancer-those who received the drug plus chemotherapy survived longer and had fewer side effects than those who received chemotherapy alone (J. Clin. Oncol. $25,669-674,2007)$. But DN-101 faltered in the phase 3 trial, which was subsequently halted in November 2007.

More recent trials have also failed to meet expectations. This past July, researchers from the MD Anderson Cancer Center in Houston reported that their vitamin D analog ILX237553 failed to provide the result they'd hoped for in a phase 1 trial of patients with solid tumors (Invest. New Drugs. doi:10.1007/s10637-0109492-5, 2010).

"So far, no clinical trial has been so positive that it has caused a sea change in cancer treatment," Jones says.

Still, several companies are working on

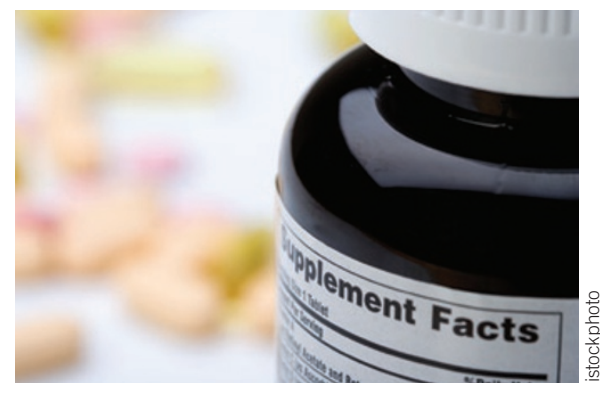

The sunny side: vitamin D stimulates cells.

new vitamin D analogs. At the Symposium on Molecular Targets and Cancer Therapeutics in Berlin this past November, researchers from the Georges Pompidou European Hospital in Paris reported that one analog of vitamin D caused a promising drop in levels of prostate-specific antigens in a phase 2 trial involving 54 men who had prostate cancer that was resistant to hormone therapies.

Meanwhile, the Toronto-based company Receptor Therapeutics has developed its own special formulation of calcitriol-OncoD102-and plans to test whether it can enhance survival in people with cancer when combined with standard chemotherapy. "There's still a lot of skepticism," say Joseph Elliot, the chief executive of Receptor Therapeutics. But "we think we can get it right."

Cassandra Willyard countries. And Asia is usually the origin of infectious disease pandemics," says Colin Blakemore, former head of the UK's Medical Research Council who holds appointments at Oxford University in the UK and A*STAR (Singapore's Agency for Science Technology and Research). "These are just a few of the areas in which everyone could gain from collaborative research efforts."

\section{Prerequisite discussion}

Bob Williamson, secretary for science policy at the Australian Academy of Science, believes that requiring cross-country collaborations such as those required by the EU's Framework Programme should also be a prerequisite for a proportion of APHMRFU grants.

"They force the best scientists from countries who have not traditionally participated in science at the highest levels to work together in the international arena," Williamson says.

Enric Banda, president of Euroscience, an organization similar to the American Association for the Advancement of Science, says that this aspect of the EU's Framework Programme has been successful. But he points to the European Research Council, formed in 2007, which bases its decisions purely on scientific excellence, as another possible funding mechanism, saying "the ideas and priority areas that are being funded aren't politically motivated; the researchers are involved in the decision making."

Mechanisms aside, the Asia Pacific region lacks an EU-style political center, which may be a potential barrier to the formation of the proposed APHMRFU, particularly when it comes to financing.

The problem of co-funding international grant schemes is evidenced by the Human Frontiers Science Program (HFSP), conceived by Japan and founded in 1989. Its aim of funding intercontinental cross-disciplinary teams is similar to the proposed APHMRFU, but it has a narrower scope and different agenda, giving room for coexistence.

Japan expected that many countries would join and share the cost. Indeed thirteen individual countries and the EU now fund the HFSP. Australia, which joined in 2004, contributes approximately $1 \%$ of the $\$ 60$ million budget. Japan, however, remains the primary contributor-currently providing just over half of the total funds.

Given this history, Butt explains that the new APHMRFU venture "has to be truly inclusive and collaborative to succeed; it cannot be driven by a single nation."

Branwen Morgan 